ENTREVISTA 


\title{
Peter Brown en Barcelona
}

\author{
Consell de Redacció de Medievalia ${ }^{1}$. \\ Universitat Autònoma de Barcelona \\ Institut d'Estudis Medievals \\ 08193 Bellaterra (Barcelona). Spain
}

\section{Resumen}

El prestigioso historiador irlandés P. Brown ofrece, a través de una entrevista, un repaso a algunos temas que han centrado sus investigaciones. Profundiza sobre aspectos de la Antiguiedad Tardía, la religiosidad y el pensamiento de los Padres de la Iglesia y el cristianismo.

Paraules clau: antiguitat tardana, religiositat, cristianisme, patristica, purgatori.

\section{Abstract}

The prestigious irish historian P. Brown offers, in an interview, a revision of his investigations. He dives into some aspects of Late Antiquity, religiosity, thinking of patristic and of Christianity.

Key words: Late Antiquity, religiosity, christianity, patristic, purgatory.

El Instituto de Estudios Medievales de la Universidad Autónoma de Barcelona y el de Cultura Medieval de la Universidad de Barcelona organizaron en dicha ciudad, entre los días 26 y 28 de junio de 1996, la XXIV Semana Internacional de Estudios Medievales dedicada al Hecho religioso en la edad media. Entre las relevantes figuras que participaron en dichas jornadas, se contó con la presencia de uno de los investigadores más prestigiosos de las últimas décadas; el profesor, y especialista en Historia Antigua, de la Universidad de Princeton, Peter Brown. Este ilustre dublinés que ha venido desvelándonos, a lo largo de los años, en sus estudios, los secretos de algo tan complejo como son los niveles culturales de la santidad, pronunció una conferencia que giró en torno a la Religiosidad en la antigüedad tardía. Durante su estancia en la ciudad con-

1. Entrevista realizada en Barcelona el 27 de junio de 1996 por: Juan José Cortés, Daniel Durán, Xavier Gil, Javier Robles, Francisco J. Rodríguez, Joan Ruiz, Vicenç Ruiz y Núria Silleras. 


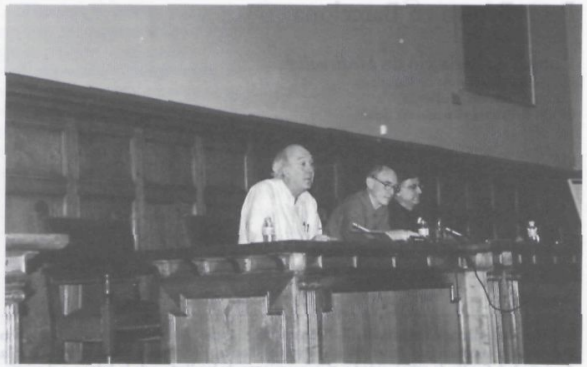

Perer Brown, William Christian y J.E. Ruí Domènec en el Aula Magna de la Universitat de Barcelona, 26 de jusio de 1996

dal tuvo la amabilidad de conceder una entrevista al consejo de redacción de MEDIEVALA, el contenido de la cual publicamos en estas páginas.

- La doctrina cristiana alto medieval, a través de la interioridad de su discurso, afianzó la creencia, en el seno de su comunidad, de que únicamente existía la salvación o la condena eterna. Pero, a finales del siglo XII, ante la necesidad de dar una respuesta menos fatalista, dicho discurso encontró una salida, el purgatorio, ese lugar donde las almas de los que mueren en gracia, sin haber hecho en esta vida penitencia alguna por sus culpas, satisfacen la deuda con las penas que padecen para después gozar de la gloria eterna.

¿Qué explicación daría usted al porqué de la Invención del purgatorio?

En primer lugar, quisiera hacer una pequeña puntualización; el purgatorio para los bizantinos, coptos, sirios, etc., es decir, el cristianismo oriental, nunca tuvo una fisonomía sacralizada como en Occidente. Pero ese no es el problema. El verdadero reto es poder llegar a precisar por qué un pequeño grupo de cristianos, a lo largo de la antigüedad tardía, transitó hacia esa noción del purgatorio. Para ello, como muy bien ha subrayado usted, es necesario explicar qué entendemos por interioridad de la ética cristiana, pues es ahí donde residen los principales hechos que dificultan la consecución de nuestro fin. Debemos dar una respuesta a la proposición planteada por ese movimiento denominado autocristianización, es decir, al monacato. 
Los hombres y mujeres que optaron por organizar sus vidas en el interior de dichas comunidades, se entregaron a un gran esfuerzo: seguir la estrecha línea marcada por los Evangelios. Debido a ello, en el núcleo de estas congregaciones, se desarrolló un sentimiento interior del cual derivó el concepto de pecado, que tuvo su origen en las impresiones causadas en el alma por las cosas espirituales, sin que se hubiera dado todavia el paso definitivo que transformó los valores y que condujo del pecado de hecho al pecado eterno.

San Gregorio Magno y san Agustín fueron los que transmutaron lo uno en lo otro al someter todas las acciones humanas a una normalización. Es cuando la patrología transitó hacia lo mental y se interesó únicamente por aquellos fenómenos que afectaron a la psique humana en el transcurso, día a día, de la sacralización de la vida. A partir de ese instante, los grandes pecados del cristianismo primitivo, como la idolatría o el adulterio, cayeron en manos de esa revolución cognitiva, tradición en donde el monacato encontró sus fuerzas. Pequeños núcleos, cierto, pero con una influencia enorme gracias a un "arma” de la cual carecíeron el resto de los mortales: la escritura.

Llegados a este punto, me asaltaron las dudas y es cuando me planteé la siguiente pregunta; ¿̇por qué ese paso no fue dado en el seno del Imperio bizantino donde el monacato también alcanzó una sensibilidad ascética, superior incluso a la propia idea del purgatorio?

Tal vez porque el bizantino siempre creyó en una última salida, la del perdón divino, pues, para él, Dios era el verdadero emperador de la prerrogativa $y$ de la compasión. Era natural que los hombres, al ser materia, pecaran, razón de más para que se impusiera la gracia divina.

Ahora bien, donde nunca existió una verdadera estructura imperial sujeta a un dios soberano e indulgente, el modelo se quebró; en Irlanda, ese mundo oscuro y sombrío escapó a Roma. Allí era imposible que existiera el concepto de amnistía, por lo que cada hecho, cada pecado, debió ser recordado de forma oral.

En Arabia, el islam trajo consigo otra respuesta: la de una soberania divina sin opción a demandas y a prerrogativas.

Cuando Jacques Le Goff, desde el medievalismo, se enfrentó en su excelente libro La invención del purgatorio al problema que aquí estamos debatiendo, lo hizo sin situarse en otras posibles realidades. Ahora bien, si lo planteamos desde la tardoantigüedad, esos modelos imperiales basados en la amnistia nos darán respuestas muy diferentes.

Tomemos el ejemplo defendido por Eustacio, un escritor de Constantinopolis y contemporáneo de san Gregorio Magno. Seguidor de una creencia muy difundida en la época, sostenía que las almas de los muertos no permanecían dormidas en la tierra hasta la llegada del juicio final, sino todo lo contrario, era partidario de que esas almas tenían varias vidas, motivo por el cual, el pecado personal, no tenía razón de ser. Cada alma "escribías su propia biografía pero no en función los pecados personales.

2. Le Goff, J.: La naissance du Purgatoire. Paris, Gallimard, 1981. 
Mientras que, desde la otra corillaw, san Gregorio Magno, en el Libro Cuarto de sus Diálogos, se mantenía firme en la idea de que los méritos personales sí tenían continuidad en el mundo de las almas.

- Hubo una primera etapa, en la historia del cristianismo, en la que se aceptó el sincretismo como método útil para su difusión, a pesar de tratarse ya de una religión de carácter universal. ¿̇Esos primeros pasos fueron dados más por necesidad que por convicción? y, ¿no es cierto que se trató de otra oportunidad perdida de haber podido alcanzar un modelo de historia más integrador y no el modelo teórico de un cristianismo basado en la negación de las otras culturas?

Cierto, fue una auténtica oportunidad perdida que podría haber dado lugar a un cristianismo, por lo menos, más tolerante. Personalmente, me ha llevado mucho tiempo el poder llegar a comprender la razón que se oculta detrás de este gran problema. Esa falta de consideración, hacia una posible pluralidad de ideas o prácticas diferentes, tiene su origen en los textos cristianos. En ellos se hace evidente que la acción fue llevada a cabo por personas que nunca creyeron en orras tendencias más favorables, en criterios no tan cerrados, y menos en colaborar con quienes los propugnaban. Dicha actitud lo único que pretendió fue adelantarse a cualquier evento que pudiera dificultar o impedir sus pretensiones. Transformó al cristianismo en una historia conscientemente desconocida.

Cuando uno se entrega por primera vez a la lectura de esos textos cristianos, cree estar frente a obras de gran claridad y consistencia. Sólo si somos capaces de llegar a leer entre líneas podremos constatar que se trata de una sensación falsa; las historiografías, hagiografías y biografias reúnen en su interior modelos torpes y triunfalistas y esa misma impresión se ve incrementada al leer a cualquier autor de la cultura grecorromana o del mundo islámico.

El estudio comparativo es el que me ha conducido a esta interpretación de los hechos. Si tomamos el islam de los primeros tiempos, el que se apoderó del creciente fértil y, mucho más tarde, en el siglo XVI, el de la corte turca, por ejemplo, podremos observar como nos encontramos, de manera paradójica, frente a un islam fuerte, dominante y cerrado sobre sí mismo, pero que, en sus relaciones internas, al tratarse todavía de una religión de transmisión oral, era mucho más abierto que el cristianismo.

El proceso de cristianización, de una zona, de entrada, podría parecernos mucho más sincretista pero, y ahí está la trampa, los obispos siempre actuaron al amparo del sector más severo y riguroso de la Iglesia.

- Averil Cameron, en su libro Christianity and the Rhetoric of Empire. The Development of Clristian Discourse ${ }^{3}$, habla de tres modalidades diferen-

3. Cameron, Averil: aChristianity and the Rhetoric of Empire: The Developpment of Christian Discoursen. Berkely, Los Angeles: University of California Ress, 1991 (Sather and Classical Lectures; 55). 
tes del lenguaje en el discurso del cristianismo primitivo: el oral, el escrito y el visual. ¿Cuál es su valoración sobre este último en el seno del primer cristianismo y cómo cree que influyó en la importante iconografía medieval?

Creo que el libro de Averil Cameron, al explicar la universalización del cristianismo y al proponer un modelo que evite otros de mayor confrontación, se ha convertido, en la actualidad, en una de las obras más importantes que sobre la Antigüedad Tardía se han escrito.

A pesar de todo, su trabajo, al seguir una de las tendencias propuestas por el posmodernismo, no deja de ser idealista y teleológico al sostener que el cristianismo había descubierto un discurso que estaba destinado a triunfar. En realidad, la cosa no fue tan sencilla como a primera vista pueda parecer, todo lo contrario, ésta se caracterizó por su complejidad. Ese discurso totalizador y cognitivo, al contrario de lo que mantiene Averil Cameron, no se había dado todavía.

- En las comunidades del norte de África la difusión del islam fue muy rápida y aquí se ha apuntado la posibilidad de un Islam como modelo alternativo al cristianismo. ¿Qué sucedió en realidad para que aconteciera dicho fenómeno? y, ¿cómo convivieron cristianos y musulmanes en los inicios de este proceso?

Si algo me ha llamado siempre la atención, no es otra cosa que la enorme diferencia existente entre el Magreb y el Próximo Oriente y, el porqué de esa discordancia.

A pesar de que ambos mundos son islámicos, la desigualdad radica en el hecho de no compartir un pasado común. Por un lado tenemos un Próximo Oriente heredero del desaparecido Imperio sasánida, el prestigio del cual fue delegado en las comunidades coptas y sirianas, frente a un Magreb donde sucedió todo lo contrario. Allí los nuevos actores se encontraron con un escenario que les era totalmente desconocido. Un norte de África en el que la toponimia de origen romano seguía dando nombre a ciudades como Hipona o donde, en pleno siglo $\mathrm{Xl}$, se seguía hablando latín como sucedía en el caso de Túnez. Pero algo jugó a su favor, primero, que esas ciudades, al ser poco relevantes, no tuvieron necesidad de crear una burocracia, lo que aceleró su proceso de asimilación. Ciudades que formaron parte de reinos sureños, descentralizados, que cayeron en manos de clases castocráticas que sometieron el territorio a un proceso continuado, no carastrofista, que eliminó para siempre la diversidad. Un Magreb donde precisamente la conversión de esos abárbaros» a un islam que carecía de renombre fue lo que le confirió una mayor preponderancia pero que se apartaba, cada vez más, del otro islam, el de la Hispania fatimida y el de Egipto y Siria, donde el éxito de los árabes sí se hizo deudor de la burocracia cristiana.

En lo referente a la convivencia entre ambas comunidades, queda testimoniada, por poner algún ejemplo, en las inscripciones funerarias de las tumbas del siglo Xl, la época del papa Gregorio VII. 
- Parece ser que el cristianismo no se impuso de forma rápida en Occidente, que en realidad se trató de un proceso lento que tuvo que superar grandes dificultades en algunas zonas. ¿Es posible que la razón a dicha oposición fuera debida a la profunda interioridad politeista de la sociedad romana?

Es cierto que tenemos tendencia a infravalorar la diversidad del cristianismo, no la que podamos encontrar a nivel personal, sino la local, es decir, aquélla que hace que el proceso de cristianización no sea igual en todas partes. ¿Cuántas veces hemos oido hablar de la supervivencia de tradiciones paganas en el seno del cristianismo?. Pues bien, esa afirmación es falsa dado que, el cristianismo, no concedió nunca esa gracia. Veamos algunos ejemplos. ¿Quién no conoce la festividad de san Juan Bautista, una conmemoración hoy cristiana pero que, en realidad, tiene un origen pagano que se remonta a un antiguo ritual campesino en el que se procedía a la limpieza de los campos y donde se realzaba la figura del agua, vital para quienes dependían, única y exclusivamente, de los frutos de la tierra? Se trataba de unas jornadas donde quedaba bien clara la importancia del trabajo en asociación. Pues bien, en tiempos de san Cesáreo, en el siglo VI, el Cristianismo reconvirtió dicho acto al que le sumó el bautismo. ¿Podemos hablar de supervivencia de un acontecimiento pagano? No, y sí de una forma de cristianizar que aprovechó un acto colectivo para facilitar la conversión de un núcleo organizado.

También se ha tendido a sobrevalorar la labor misionera que era atribuida, de manera exagerada, a una iniciativa estatal. El error procede de la mala interpretación que se ha hecho de la historiografía bizantina. En poner demasiado énfasis en hacer creer que era el emperador, en persona, quien enviaba a esos hombres de Dios.

En realidad no sucedio así, por to menos en las zonas más apartadas de Occidente donde la cristianización partió de iniciativas propias, personales o familiares, baste citar los ejemplos de san Patricio en Irlanda o el de la Britania tardorromana. En esos rincones tan remotos no hubo necesidad de contar con una iglesia organizada, controlada por sacerdotes y obispos a pesar de que el orden cristiano, su esratus, fuera respetado. Se trató de un cristianismo de frontera que había perdido sus rasgos más comunes, el de una estructura bien organizada, pero que sobrevivió a las adversidades al aceptar el papel de religión familiar durante siglos. Como podemos ver, entonces, nos situamos frente a un modelo cristiano que no es ni el monacal, ni el estatal. Un modelo hagiográfico muy distinto al que podamos encontrar en los textos cristianos tradicionales.

- La Iglesia irlandesa, esencialmente monástica, se desarrolló, gracias a la labor misionera, al margen del modelo de organización política de la Iglesia romana de la antigüiedad tardía. ¿Acaso se produjo un conflicto de poderes, en aquellas zonas menos romanizadas de Occidente, entre la utoridad central del obispo y el hombre santo misionero líder de la comunidad cristiana local? 
La historiografia de las relaciones de los obispos con los hombres santos es muy abundante. Los textos de los historiadores romanos cristianos hablan de una religión que triunfó, pero que se mostró siempre indiferente frente a la alteridad, al pagano. A ello hay que unir las dificultades con las que se encontraron los obispos, es decir: el tiempo, la distancia y las comunicaciones. En otras palabras, esa fue la razón que justificó la necesidad de "cultivar" a los hombres santos. Pero la realidad era otra bien distinta, la de controlar a los campesinos. Por ese motivo, estos hombres santos que, en realidad, nunca estuvieron marginados, fueron tan necesarios.

- Durante mucho tiempo se sostuvo la tesis de que la caída del Imperio romano se debió a problemas políticos, económicos, sociales, invasiones bárbaras, etc. pero usted, en su libro El cuerpo y la sociedad ${ }^{4}$, afirma que, en realidad, el factor determinante fue la derrota del cuerpo, que ésta marcaría el final de la antigïedad y el principio de la edad media. Entonces, ¿dónde situaría usted hoy todas esas explicaciones construidas en torno a esta frase?

Tomé la misma de un ensayo de mi buen amigo Jacques Le Goff, pues pensaba que, al usarla, podría llegar a dar una explicación de aquello que me interesaba, es decir, el fenómeno de la caída del Imperio romano, argumentando que se trató de un hecho silencioso que no significó nada para Occidente. Para mí eso era lo más importante. Ahora bien, epor qué defiendo la idea de que dicha caída se manifestó a través del cuerpo, y que su concretización, aquello que completó el proceso, fue sólo un factor occidental?

San Ambrosio, a través de san Agustín, mantuvo la idea, pues creía en ella, de que el modelo que debía seguir la Iglesia católica, lo que la convertiría de verdad en una comunidad perenne e inviolable, sería el celibato. Que su reducción a lo más esencial y seguro, se realizaría en los cuerpos inviolables de los monjes y en el de los sacerdotes, aunque en éstos últimos fuese de forma eventual. Sin embargo, ese celibato que no estaba generalizado en Occidente y que se convirtió en requisito indispensable, es cuestionado al tratarse de hombres doctos y ordenados, de obispos y sacerdotes que podian estar casados.

He aquí la razón por la que me decidí a enfocar, desde una perspectiva distinta a la de Le Goff, la derrota del cuerpo. No desde la sacralización individual, sería una interpretación demasiado optimista, y si desde una perspectiva puramente simbólica. En otras palabras, sólo alcanzaron ese carácter sagrado los que fueron fieles, en el seno de la comunidad eclesiástica se entiende, a la idea de que ésta, al ser perpetua e inviolable, estaba por encima, incluso, del Imperio.

- ¿Por qué la moral cristiana terminó imponiéndose a la de otros grupos de vulnerables que también buscaban la paz en el interior del mundo romano?

4. Brown, P,: The Body and the Society: Men, Women and Sexual Remunciation in Early Christianity. New York. Colkumbia University Press, 1988. 
La expansión del estilo de vida y de la moral cristiana a lo largo y ancho del Imperio romano es un problema al que no pude dar respuesta en mi primer libro, The World of Late Antiquity ${ }^{5}$, al no contar entonces con un mayor conocimiento del derecho romano.

Después de la publicación de mi estudio, han sido editadas obras muy importantes cuyo tema principal de investigación es precisamente éste: el derecho romano en la legislación matrimonial en época de Constantino o las leyes que fueron dictadas contra la magia, al ser considerada ésta un crimen universal, una herejía, un pecado. Estos trabajos han venido a demostrar que efectivamente en el siglo IV se dió la convergencia de dos corrientes, la cristiana y la imperial. El nexo de unión, el pilar sobre el que se apoyó el triunfo del cristianismo, como ya indiqué con anterioridad, fue el derecho romano.

- ¿Qué es lo que hizo que el cristianismo tuviera esa necesidad imperiosa de modelos hagiográficos y que eso al final se convierta en una verdadera anarquía, la cual se prolongó hasta que Lutero en cierta manera, puso orden? ¿Por qué se dio un fenómeno tan sintomático?

En realidad se trató de un movimiento pendular, pues todas las etapas en las que el sincretismo prosperó fueron seguidas de otras en las que se produjo un avance de las obras de los grandes patriarcas como san Bonifacio, sin ir más lejos.

Déjenme que les ilustre con un ejemplo: hace un par de días, en Estambul, pude ver como en cada mezquita han sido colocadas unas placas en las que se puede leer lo siguiente: «En el interior de este recinto queda prohibido encender fuego, besarse, arrojar monedas, etc., por tratarse de prácticas no musulmanas. Son pecado. Sólo está permitida la lectura del Corán».Hace cinco años esos rótulos no existian. ¿Por qué les he contado todo esto? Porque, ¿quién no ha oido hablat hoy del integrismo islámico? Cuando se trata dicho tema en la actualidad se hace de manera banal, porque quienes opinan sobre él no se dan cuenta de estar situados frente a un islam que se está autodefendiendo, no de Occidente, como algunos piensan, y si de los sincretismos que amenazan, dia a día, su integridad. Ésa es la razón que lo convierte en integrista.

A mi entender, en el seno de la cristiandad tardoantigua y altomedieval se dio ese mismo proceso. Una cristiandad que, ante la obligación y la necesidad de tener que integrar a todas las exigencias nacidas de lo cotidiano, se vio obligada a mostrarse aperturista, pero que, en realidad, siempre estuvo supeditada, en la sombra, a la voluntad de los grupos más escrupulosos del cristianismo.

Los ataques de san Agustín contra aquellos cristianos que seguian besándose en la puerta de las iglesias estaban justificados, no tanto por el hecho del beso en sí, sino por las críticas que se derivaban del bando contrario, los no cristianos y, sobre todo, de sus filósofos que contraatacaban con frases como aquello que es bueno para vosotros también lo es para nosotrosn.

5. Brown, P.: The World of Lase Antiguity. London: Thames and Hudson, 1971. 
Paulino de Nola, oponiéndose a san Agustín, aprovechó la ocasión para escribir una poesia, de talante sutil, en la que describía como todas las personas que acudían al templo de San Félix de Nola se besaban antes de entrar en el mismo. Por esas mismas fechas san Agustín, que era amigo de Paulino, presentó ese beso como una práctica semipagana, de mala educación, un ejemplo que se apartaba de la correcta práctica cristiana.

Otra de las características comunes, tanto en el mundo cristiano como en el romano, fue la noción de "superstición". Los pensadores de la Iglesia siempre pretendieron hacer ver que esa "superstición» era un defecto que sólo se daba en los otros, es decir, en los paganos. La superstición romana también se justificaba por los mismos principios, pues no era otra cosa que la clara manifestación de miedo a lo desconocido, en este caso a los que no profesaban sus propias creencias.

San Agustín entonces afirmó que sólo la fragilidad humana justificaba las creencias supersticiosas, una idea que hoy nos puede parecer banal, pero que, en su día, fue una aportación revolucionaria, dado que recatalogó todas las categorias supersticiosas y religiosas.

- El cristianismo alcanzó su objetivo al convertirse en la principal religión de la sociedad romana. Sus clases dirigentes creyeron entonces haber hallado en él el instrumento que permitiese la reestructuración y, a su vez, el fortalecimiento del ya debilitado poder político.Pero, ¿̇legó Roma a ser consciente en algún instante de que, en realidad, dicha universalización de la religión cristiana la abocaba, de manera irreversible, a la desaparición de su Imperio?

Uno de los aspectos que siempre me han llamado más la atención, es la característica principal del llamado "paganismo romano", la no centralización de sus funciones sociales, es decir, todo lo contrario a lo que propuso el pensamiento cristiano. El culto a los dioses podía ser afrontado desde posturas bien distintas: filosóficas, de amor, etc., pero sin la necesidad de integrar dichas conductas en una institución religiosa. ¿Por qué no?, un filósofo podía ser muy religioso y no estar obligado a formar parte de una comunidad religiosa. Se veneraba a los dioses, claro que sí, se les tributaban sacrificios, procesiones, cantos sagrados, se les adoraba y suplicaba a través de ofrendas y dones, pero, todo ello, a diferencia del cristianismo, sin la necesidad de pertenecer a un grupo concreto. La moral era laica, familiar, ciudadana.

Sin embargo, la filosofía, el culto y la moral, entraron a formar parte de un todo, dando lugar al nacimiento de una nueva teocracia que hirió de muerte al paganismo romano. El cristianismo pasó a ser la religión de todo aquél que quisiera ser y sentirse cristiano, rico o pobre, enfermo o sano, ciudadano o no ciudadano. Los sólidos cimientos del Imperio comenzaron ser excavados, y no de manera metafórica, todo lo contrario; el siglo tercero es el de las catacumbas, kilómetros de galerias obra de una comunidad entera que fue capaz de unir todas sus fuerzas para poder sobrevivir como Iglesia y, la idea que poda- 
mos tener hoy de iglesia, su significado, se aparta muchísimo de lo que pudo llegar a representar para el cristianismo tardorromano: la iglesia, la domus epis$c o p i$, no era un edificio aislado, sino que correspodía a todo un barrio cristiano, al espacio exterior y no al interior creado por cuatro paredes. Ése es el escenario que, a partir de ese instante, podrá prescindir de la ciudad. Por lo tanto, no nos engañemos, la verdadera víctima del cristianismo no fue el Imperio, pues, como ya habiamos visto con anterioridad, el Imperio de Dios y el Imperio de los emperadores llegaron a ser homónimos. A quien en realidad se sacrificó fue a la ciudad antigua. 


\section{PETER R. L. BROWN}

Dublín, Irlanda, 26 de julio de 1935.

\section{Formación}

Aravon School, Bray, Co. Dublín. Irlanda.

Shrewsbury School, Shrewsbury. Inglaterra.

New College, Oxford. Recibiendo honores del primero de clase en 1956.

\section{Trayectoria}

Investigador asociado al All Souls College, Oxford, 1956-1972.

Conferenciante de Historia Medieval en el Merton College, Oxford, 1970-1975.

Lector universitario en Fstudios bizantinos y de la romanidad tardía. All Souls College, 1972-1975.

Profesor visitante en la University of California, Berkeley, enero-marzo 1975.

Profesor de Historia Moderna del Royal Holloway College, University of London, 1975-1977.

Profesor de Historia y del Mundo Clásico en University of California, Berkeley, 19781986.

Profesor visitante del Departamento de Historia, Princeton University, 1983-1986. Profesor visitante. Universidad de Padua. Noviembre-diciembre 1985.

Profesor visitante del Departamento de Historia de UCLA. enero-marzo 1990.

Profesor de Historia. Princeton University. Desde 1986.

\section{Bibliografia:}

\section{Libros}

Augustine of Hippo. London: Faber, 1967.

Religion abd Society in the Age of Saint Augustine. London: Faber, 1971. (Colección de articulos)

The World of Late Anriquity. London: Thames and Hudson, 1971.

The Making of Late Antiquity. Cambridge: Harvard University Press, 1978.

The Cult of the Saints. Chicago: University of Chicago Press, 1982.

Society and the Holy in Late Antiquity. Berkeley: University of California Press, 1983. (Colección de artículos)

The Body and Society: Men, Women and Sexud Renunciation in Early Christianity. New York: Columbia University Press, 1988.

Power and Persuasion in Late Antiquity: Towards a Christian Empire. Madison, Wisconsin: University of Wisconsin Press, 1992.

Authority and the Sacred: Aspects of the Christianization of the Roman World. Cambridge: Cambridge University Press, 1995.

The Rise of Western Christendom: Triumph and Diversity, A.D. 200-1000. Oxford: Blackwell, 1996. 


\section{Articulos:}

"A Social Context to the Religious Crisis of the Third Century A.D.». The Center for Hermeneutical Studies. Colloquy 14. 1975. p. 1-13.

"Parthians and Sasaniansw. Persia: History and Heritage. Borte, John A. (ed.). London: Henry Melland, 1978. p. 24-30.

"Islamn. New York Review of Books. n. 26. 22 febrero 1979. p. 30-33.

*The Philosopher and Society in Late Antiquity". The Center for Hermeneutical Studies. Colloguy 34. 1980. p. 1-17.

«Dalla 'Plebs romana' alla 'Plebs Dei': Aspetti della cristianizzazione di Roma». Passatopresente 2. 1982. p. 123-145.

"The Saint as Exemplar in Late Antiquity", Representations 1. 1983. p. 1-25.

a Augustine and Sexualityn. The center for Hermeneutical Studies. Colloquy 46. 1983. p. 1-13.

"The Saint as Exemplar." Persons in Groups. TrexLer, R.C. (ed.). Binghamton, New York: SUNY Press, 1985. p. 183-194.

"Sexuality and Society in the Fifth Century A.D.: Augustine and Julian of Eclanumn. Tria Corda: Scritti in onore di Arnaldo Momigliano. GABBA, E. (ed.). Biblioteca di Athenaeum. Como: New Press, 1983. p. 50-70.

"Late Antiquity and Islam: Parallels and Contrastsn. Moral Conduct and Authority: The Place of Adab in South Asian Islam. Metcalf, Barbara Daly (ed.). Berkeley: University of California Press, 1984. p. 23-37.

«Antiquité tardiven. Histoire de la vie privée, ed. ArIÉs, P.; DUBY, G. (eds.) Paris: Le Seuil. 1985. vol. 1 p. 226-299.

eThe notion of Virginity in the Early Church». Christian Spirituality. MCGINN, B.; MEYENDORFF, J.; LECLERCQ, L. (eds.). New York: Crossroad, 1985. p. 427-499.

„Pagans and Christiansw. New York Review of Books 34.12 de marzo de 1987. p. 24-28. arnaldo Dante Momigliano*. Proceedings of the British Academy 74. 1988. p. 407-442. "Bodies and Minds: Sexuality and Renunciation in Early Christianity». Before Sexuality. HALPERIN, D.M.; WINKLER, J.J.; ZeITLIN, F.I. (eds.). Princeton University Press. 1990. p. 479-493.

"Islam medievale: una 'religione del libro' e le sue tradizioni.» L'Europa e il Mondo nel Medio Evo. CracCo, G. (ed.). Turin: Socità editrice internazionale. 1992. p. 82-94. Introducción a «Augustine's Confessions». Traducción de F.J. Sheed. Boston: Hackett. 1993. p. IX-XXVI.

"ll filosofo e il monaco: due scelte tardoantiche." Storia di Roma III. L'età tardoantica: 1 Crisi e trafformazioni. SCHIAVONE, Aldo; GRACCO RUGGINI, Lellia (eds.). Turín: Einaudi. 1993. p. 877-894.

"The Problem of Christianization: Raleigh Lecture 1992w. Proceedings of the Bristish Academy 82. 1993. p. 89-106.

"Review of Thomas F. Mathews." The Clash of Gods: A Reinterpretation of Early Christian Art. The Art Bulletin 77. 1995. p. 499-502. 


\section{Miembro de Instituciones}

Royal Historical Society.

British Academy.

American Academy of Arts and Sciences, 1978.

Medieval Academy of America.

Royal Netherlands Academy of Arts and Sciences, 1991.

American Philosophical Society, 1995.

\section{Distinciones}

Premio Arts Council of Great Britain, 1967 por Augustine of Hippo.

Honoris causa en Teologia por la Université de Fribourg. Suiza, 1974.

Doctor en Humanidades por la University of Chicago, 1978.

Grant of the American Council of Learned Societies, 1979.

Beca John D. and Katherine MacArthur, 1982-1987.

Beca Simon Guggenheim, 1989-1990.

Honoris causa en Letras. Trinity College. Dublín, 1990

Premio Ralph Waldo Emerson 1989 por Body and Society.

Premio de la American Academy and Institute of Arts and Letters 1990 por Body and Society.

Honoris causa en Letras por la Wesleyan University, 1993

Doctor en Humanidades por la Tulane University, 1994.

Premio Heineken de la Amsterdamse Stichting voor Geschiedenis, 1994.

Visiting Scholar's Stipendium de la Carl Friedrich von Siemens Stifung. Munich, 1995. 